\title{
Constructivist Approach To Information Security Awareness In The Middle East
}

\author{
Mohammed Boujettif (boujettif@yahoo.com) \\ Dept. CS, University of Liverpool \\ Liverpool L69 3BX, United Kingdom
}

\author{
Yongge Wang (yonwang@uncc.edu) \\ Dept. SIS, UNC Charlotte \\ Charlotte, NC 28223, USA
}

\begin{abstract}
This paper studies the application of an approach to enhance information security awareness amongst employees within middleeastern companies, in effort to improve information security. We aim at surveying the current attitudes and awareness levels of 116 employees in 22 companies towards information security. Two companies, from the group of companies, opted to implement a sample of the new approach which was developed based on a highly-employee centered methodology that is constructivist in nature. The approach aims to benefit the employees at different levels as it effects and encourages employee learning autonomy. The significant findings and results of this study were: (1). $91 \%$ of the employees in the case-study preferred the new approach (constructivist ISA) as opposed to current approaches conducted by their own companies. (2). $94 \%$ of the employees surveyed were dissatisfied with their companies' current information security programs, which were not interactive but completely passive in nature.
\end{abstract}

\section{INTRODUCTION}

The initial aim of this research is to ensure that CIO's and end users improve their awareness regarding risks associated with utilising information technology and appreciate that their awareness and attitude is just as important if not more important when it comes to improving information security.

Attitudes play an important role in information security behaviour and we begin our investigations by initially assessing the views and attitudes of 30 CIO's and 240 employees in 30 companies regarding their attitudes towards information security, we attempt to confirm the suggestion that poor and negative attitudes towards information security is correlated to bad information security behaviour.

In order to do the above we seek to find out firstly, whether the companies have poor information security by interviewing the CIO to establish their current information security levels and then conduct questionnaires to determine the employees' attitudes and comparing the results to see whether there is the suspected correlation.

We then move on and chose two companies' who we have established have poor information security and whose employees exhibit negative and/or poor information security attitudes and with them, we attempt to develop an information security campaign based on constructive methods which are known to promote positive changes in the attitudes of individuals with a specific goal of changing and improving employees' attitude and awareness towards information security. Then we survey the case-study participants to establish whether the information security behaviour has improved or changed their attitudes for the better.

The objectives of the paper are to answer the following questions which we hope will contribute to the constructive approach to enforce information security: Correlation between the information security levels and attitudes towards information security in middle-eastern companies; Correlation between information security levels and attitudes towards information security in middle-eastern companies; Usefullness of constructivist teaching and training methodologies to improve information security awareness.

In order to carry out the investigation, we need to find out whether the current security propaganda is likely to affect awareness and attitudes of the employees. In particular, we need to interview 30 Security Professionals/CIO's and conduct questionnaires on 360 employees from 30 different Saudi Arabian (KSA) companies to get their opinions regarding information security (IS). It is expected that most of the KSA companies have some sort of security awareness campaign or survey going on which attempts to raise awareness and highlight the risks of information security but do they measure the effects of such campaigns on the employees' attitudes and behaviour? How do they know that the campaigns have worked? Do the campaigns really improve users' attitudes and behaviour towards information security?

The project evaluates the attitudes and awareness of security professionals and employees in the Middle East and how their behaviours and personalities affect their views towards information security. A set of measurable security metrics are identified and used to assess the employee's attitudes and awareness towards information security. The results of these assessments will be used to establish effective security campaigns based on constructivist approach that improve and prompt positive attitudes and perception towards information security. This approach can be viewed as an individualised user-centred free learning environment where users are in control of their own learning process. Up to our knowledge, investigation has never been applied in the context of information security or IT security, and makes this project unique and we hope will add to the knowledge area in this respect.

\section{BACKGROUND AND RELATED WORKS}

The term Information Security traditionally conjures up images of complex technical hardware and software methods that can only be implemented if one employs a professional company which specialises in Security or Information Security to be exact. Though hardware and software technicalities are important, the users of information systems are often ignored as the most critical ingredient in a secure information technological system.

Indeed previous researchers, like Stanton et al [20], Schneier [20], and Katsikas [11] have warned that it's not only the technical software or hardware aspects that introduce vulnerabilities into an information system, rather it's the users of the system which pose the greatest and most serious information security risk. It is the human element which needs to be dealt with first and foremost.

Therefore an effective Information Security Awareness Programme plays an important role as it seeks to influence and improve the users' education, training, and guide their understanding of the concepts involved with the aim of improving their security behaviour and attitude towards it.

Training assumes that users should be educated towards improving their competencies to face rapid technological change and the amount of training individuals receive during their working life has a significant impact on their career prospects, wages and employability. Training and education in a subject or concept has a tendency of 
effecting the perceptions and attitudes towards that subject or concept and there is some indication that the environment and the way the subject matter is presented have a lot to do with the individuals' perception (Ann, Timothy and Laubach [2]).

Even though changing or improving attitudes and perceptions towards something is rather challenging, and this has been attempted in many spheres of life and in general people react by avoiding and moving away from those things that they have bad perceptions of, especially those items they perceive difficult, constraining or limiting. This is most readily exemplified in the fields of academia/training where peoples' dislike of challenging subjects (such as Science and Mathematics) possibly due to the perceptions that such subjects are likely to develop, in them, a sense of failure or contribute to negative feelings due to the prospects of unsatisfying results or grades. Their attitudes and perceptions towards these subjects are negative to the point that they avoid them completely and this may be reflected in the drop in number of enrolments made for those subjects at University level.

Thus it would make sense that companies concentrate their efforts on introducing and/or improving their information security awareness (ISA) programmes to ensure they target and improve their employees' attitudes towards ISA have an effective and secure information system. This is not true for westernised companies as it is for their Middle Eastern counterparts, who are far less developed in this field, and still have much to learn.

1) Attitudes, Perceptions, Learning Methods, and Training: Information Security awareness within Middle East has become increasingly more important and many more companies in the region are now taking it more seriously, probably due to Information Technology systems becoming the chosen medium for doing business. Within the larger more established companies which may also be internationally spread, information security awareness programmes are firmly established and have really been supplanted from their home bases. But the Middle Eastern company which is home grown, have paid little attention, certainly in the past information security awareness programmes never even existed or at the very least were little understood or appreciated. Now however, there is a growing interest in the field though they still lag behind western counterparts, especially in developing their own internal company programmes.

In particular, Saudi Arabian organizations' face internal and external threats in terms of information risk and preliminary investigations indicate that many organisations have ambiguous and ineffective policies regarding information security due to many diverse reasons among them is the all important issue of awareness and attitude towards it. Both senior management and senior security professionals had issues in this regard and that raising the general level of information security awareness through training and education of end users as well as improving their own understanding of their attitudes and awareness inclusive.

One way of increasing the penetration or appreciation of such programmes is by developing programmes which are effective, and by that we mean company employees really getting to grips with information security policies that aim to improve their awareness. But how does one know whether the programmes are effective and whether it is improving employees' awareness, changing their perceptions and building positive attitudes towards better information security behaviours.

Certainly developing an awareness programme which is effective can be considered as a programme, to a larger extent, entails the imparting of knowledge whether in a training format or in a more academic format etc. The idea is to develop a programme that works towards providing information which attempts to change unfavourable perceptions and attitudes to desirable ones that effect behaviour in a more conducive manner and aim to build and improve information security awareness. If we agree that the programme must entail elements of transfer of knowledge, information, and be in an environment of learning then it would make sense to employ methods that are utilised and observed in pedagogical circles which have been tried and tested and have yielded positive results.

The method of learning which we are most interested in, in this research endeavour, is one which has a proven track record and history of been successful in making positive changes to ones attitude and perceptions. But before we identify that method, we must get to grips with what perception and attitudes are, and what features are necessary to cause positive changes to occur.

Pickens [16] indicates attitudes govern a person's personality, belief, values, and motivations. Pickens [16] points out that an attitude includes three components: an affect (a feeling), cognition (a thought or belief), and behaviour (an action).

Individuals even try to employing interesting tactics in an attempt to reduce dissonance:

- Eliminating his/her responsibility or control over an act or decision.

- Denying, distorting, or "selectively" forgetting the information.

- Minimizing the importance of the issue, decision, or act.

- Selecting new information that is consonant with an attitude or Behaviour

With this in mind it would make sense to try to develop an information security awareness programme which reduced the cognitive dissonance, and instead, introduce a programme whose activities and features attempt to reduce dissonance (conflict), are more comforting and pleasing manner. Interestingly, Pickens [16] states that attitude formation, is a result of learning, modelling others, and our direct experiences with people and situations. And more importantly attitudes come in different strengths, and like most things that are learned or influenced through experience, they can be measured and they can be changed.

The method that will be used in measuring attitudes/preferences towards information security will be through an employee survey which comes in a form of a questionnaire that expects the participant to answer a set of questions aimed assessing their attitude/preference by indicate how strongly they agree or disagree (like or dislike) with a statement via ticking a 1-5 scale. Where 1 indicates strongly agrees with or like intensely while 5 indicates strongly disagree or dislike intensely (cf. Figure 1).

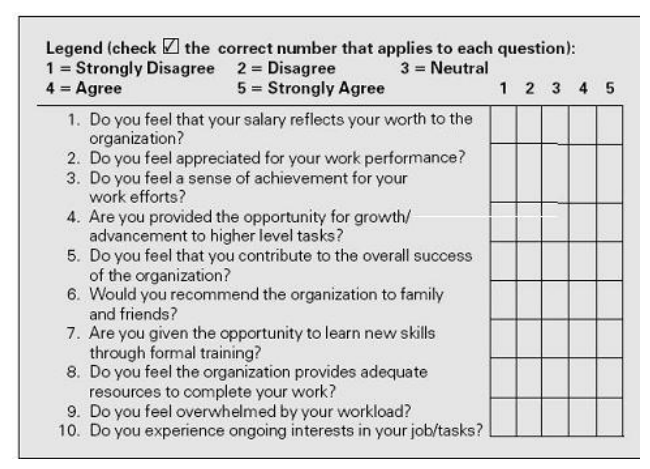

Fig. 1. Employee Attitude Survey 
Changing attitudes and behaviour towards something is difficult, and people react by avoiding those situations that they perceive as difficult, constraining or limiting. Anything that may cause a sense of failure and/or negative feelings will deter them away from it. Therefore the only way to get them to move towards it is to change their perception and Pickens [16] suggests that in order to get an individual to change their attitude you would have to address the cognitive and emotional components. By challenging someone's behaviour through the provision of new information, you would begin the cognitive process and providing new information is one method for changing a person's attitude and therefore his or her behaviour. We therefore intend to develop a number of example activities and material that are geared to providing new information in an interactive, fun and stimulating way, and the methodology which has that proven track record to do so is constructivist in nature and makes the process of learning new information challenging but memorable.

The best way to understand constructivist methodology is to look at a number of definitions from a number of scholars who best describes it. Jenkins [10] mentions that "Constructivist of different persuasion (hold a) commitment to the idea that the development of understanding requires active engagement on the part of the learner." Naylor and Keogh [15] mentions that "The central principles of this approach are that learners can only make sense of new situations in terms of their existing understanding. Learning involves an active process in which learners construct meaning by linking new ideas with their existing knowledge." von Glasersfeld [24] mentions that "Knowledge, no matter how it be defined, is in the heads of persons, and that the thinking subject has no alternative but to construct what he or she knows on the basis of his or her own experience."

Considering the definitions above, we can appreciate that by using the simple emotional disposition of like/dislike or agree/disagree towards learning of a concept or becoming more aware of information security; the preferences/attitudes of the learners (employees) are surveyed through questionnaires and interviews. We assess whether the current method of understanding/learning about information security (through their current programme) is preferred, all the surveyed programmes that were in existent followed the traditional approach where information was sent out as an email or poster warning individuals about security. Or whether they preferred our new approach based on constructivist methods, where they receive little or no instruction or explanation, but are encouraged towards an active and engaging environment with virtual independence in learning about information security. We surveyed the employees again after implementing some of the new approach to garner their attitudes/preference and behaviour. In our research we should aim to survey our learners prior to their commencement of the constructivist information security awareness programme. Furthermore, we should aim at investigating the learning environment which would help us in identifying a conducive atmosphere to ensure learning occurs without the disruptions that may come from a busy office environment.

The material, in essence, information security warnings, posters, emails and policies can sometimes be daunting and unwieldy thus the advice would be to make the material more learner-friendly and more learner-centric and even introduce activities which allowed the learner to develop their own information security material which would allow them to feel they have more ownership to gain a deeper understanding since they had constructed the material that they comprehend and understand.

The perception of science as a daunting and unwieldy, is similar to perceptions of information security encountered in this research endeavour and therefore our new approach would aim to allow users to develop material and activities that would contain their own terminology and explanations which they themselves constructed and understand.

Here we should attempt to avoid passive learning and move towards active and interactive learning and introduce the learners to relate the information security to their daily lives and how it affects them and their colleagues. Other researchers have studied the effect of active learning approaches, in academia, on academic achievement, attitude and concept learning (Anzai and Simon [3], Maria and Rosetta [14]) and they have found it beneficial and positive.

\section{Method and Realization}

A questionnaire was developed to identify the awareness level and attitudes of a number of employees from 30 companies located in the KSA and a number of CIO from the companies where are also interviewed to establish their information security level or details of any ISA programme. The questionnaires were administered to different varying sets of employees, total administered was 240 but only 116 were deemed usable.

The employees $(\mathrm{N}=116)$ were given questionnaires to complete and the CIO's $(\mathrm{M}=23)$ of each company were separately interviewed by the researcher. The answers were collated and checked for accuracy by the researcher to make sure that the employee's responses had been completed. If any response was omitted then they were removed from the sample. The questionnaires and interviews material were adapted from Questionpro.com (2007) and University of Florida IT Security Awareness (2009) (to survey information security awareness) and TCET (1997) (to survey attitudes and perceptions) and adaptations to garner respondents' attitudes and awareness of information security, in their respective work places.

After the completion of the questionnaires from the sample group, the results of their opinions were collected; again the responses were validated for consistence, to make sure that disparate answers were removed leaving only consistent data outcomes.

In addition, a single case-study entailing a questionnaire was administered on two of the companies which had agreed to test the researcher's sample material for an ISA programme that was designed on the basis of constructivist theory.

To ensure that the data gathered was consistent and valid a large pool of respondents was needed and though the initial size of the sample was 240 individuals, only 116 responded accurately and concisely, the rest of the questionnaires were never returned, or were half completed, or wrongly completed and therefore were not included in the sample.

\section{Results And Evaluation}

\section{A. Employees Preferences and Perceptions}

Our survey shows that $91 \%$ (68/75 individuals) of the employees from the case-study preferred the constructivist approached (referred to as approach two) over the traditional approach (referred to as approach one) which their company was utilising. Possibly indicating that traditional methods of disseminating and delivering ISA programmes which is more a centred approach of delivery i.e. a bunch of information and concepts delivered as detailed posters, emails, etc, may be an ineffective way of motivating employees and may have detrimental consequences for them in learning ISA and becoming more aware of ISA concepts, it may also have a negative effect on the intrinsic motivation and attitude to learning ISA concepts. Employees preferred to develop their own material (email propaganda, quizzes etc) and participate interactively with facilitative guidance from their 
Information Security facilitator (whose primary responsibility was to gather initial ISA syllabus, resource, content and material). Further to this, and in general the employees, according to this study, preferred to be left on their own to construct their own material based on the concepts of ISA now and then they engaged with the facilitator as developers rather than seeing themselves as passive, reactive, inert bags of the provider of knowledge, answer book or supplier of results.

Regardless of the vast majority of the employees indicating their degree of agreement with approach two, these employees felt that they could learn ISA concepts and become more aware of them in a more productive manner through this method than through approach one, thus indicating that CIO's should seriously think about adopting constructivist methodologies to improve ISA awareness.

Employees' enthusiasm and motivation was also higher and attitudes had transformed when approach two was implemented. It is interesting to note that while employees wanted freedom from the confines of formal passive learning, they in fact enjoyed the learning atmosphere provided by approach two, which is in keeping with academic research circles.

\section{B. Details of Results and Discussion}

1) Employees Information Security Awareness: All respondents were windows users, and $100 \%$ of those who used the internet used it to access email, while $45 \%$ used it for work related chores. $82 \%$ of respondents utilised the internet for less than an hour. When asked about their behaviours regarding how they worked with their important data and other computing habits and behaviours:

- $83 \%$ did not have current backup of their work files.

- $65 \%$ passwords were not difficult to guess or they did not know if it was difficult enough, even though $76 \%$ correctly chose from a selection of passwords the most difficult password to guess.

- $78 \%$ did not update their computers with latest updates.

This is a disquieting set of results which may indicate a real lack of training within the companies surveyed and may indicate that respondents have further issues with their Information Systems implementations in general, as well as indicators that their information security is in need of improvement. Many of the respondents indicated a really shocking low level of information security awareness in the companies they worked in, for example their internet and email usage behaviours were as follows:

- $65 \%$ did not feel really aware of current viruses and worms.

- $60 \%$ felt that they were vulnerable to attack from hackers.

- $65 \%$ either never used firewalls or did not know about it. $92 \%$ never used anti-spyware.

- $62 \%$ did not know what phishing meant.

- $56 \%$ read their emails regularly.

This may indicate that the current lack of ISA programmes or lack of current ISA programmes are ineffective and have profound consequences on information security. Even though, some did show a conscientious regard on treating virus infection and carefulness when opening emails:

- $63 \%$ felt somewhat prepared to treat virus infection while $37 \%$ felt they were not at all ready.

- $62 \%$ were careful when opening emails.

Information Security policies, procedures were little understood and rarely recognised or appreciated for example:

- $40 \%$ did not know who to contact in case of security related issues.

- $50 \%$ did not know their companies information security policies
- $77 \%$ did not know the content of the companies information security policies

- $76 \%$ had not heard of the term Information Security

- $76 \%$ were not aware of the information security policies

- $75 \%$ were not aware of the procedures of reporting information security issues.

- $88 \%$ did not know the local management ISA specialist.

- $76 \%$ claimed that their companies never published ISA material

- $48 \%$ got their security information via word of mouth.

- $39 \%$ felt email was the best way to keep them up-to-date regarding information security

A rather depressing situation is witnessed in the majority of Saudi Arabian companies which were surveyed, and may give us a reasonable microcosm of the state of information security awareness in the companies operating in Saudi Arabia, as well as give us a good possible reflection of the state of affairs in and around the middleeast, as a whole.

2) Respondents' Attitudes: Respondents' attitudes towards interactive learning as indicated by the respondents were positive:

- $57 \%$ prefer to work on real life every day challenging problems rather than theoretical problems!

- $62 \%$ say they examine unusual things

- $45 \%$ preferred to learn through interactive activities

- $40 \%$ preferred learning from a PC rather than from printed material while $22 \%$ preferred printed material rather than a PC!

- $51 \%$ prefer to using a PC while $47 \%$ prefer TV

- $88 \%$ prefer to use PC while $12 \%$ would rather write

- $83 \%$ prefer using a PC while $17 \%$ prefer to read a book

Activities that may motivate the learning of new concepts were ones which required challenging, creating and Inventing activities as indicated by the results:

- $70 \%$ prefer to find new things to work with or study

- $76 \%$ prefer to create unique things

- $75 \%$ prefer to do things themselves

- $74 \%$ prefer to invent new ways of working and share with others

- $72 \%$ prefer to invent new ways when one method does not work

When faced with a learning environment which either meant learning by oneself or in a team with colleagues the following results were garnered:

- $74 \%$ prefer asking colleagues issues they don't understand

- $67 \%$ preferred to learn through discussion with others, while $43 \%$ respondents preferred to learn on their own

- $44 \%$ felt comfortable when working with others and $25 \%$ were indifferent

- $80 \%$ prefer to see their colleagues smiling

- $90 \%$ prefer working with other especially

- $67 \%$ enjoy participating in competitions

In terms of the importance for there being an enjoying and fun environment:

- $65 \%$ preferred to work in a fun and enjoyable atmosphere

- $66 \%$ enjoy working on challenging problems and 54\% felt they try different methods to solve challenging problems

Respondents' attitudes towards information security were quite shocking:

- $50 \%$ owned up to not opening any IS email propaganda

- $58 \%$ feel that if they had read IS emails they would have benefited for the information, while $24 \%$ felt they would be non the wiser

- $45 \%$ felt that IS information was not important 
- $45 \%$ felt that IS information was difficult to understand, $37 \%$ felt they did understand the IS

- 56\% felt frustrated when they could not understand something, and it annoyed them tremendously and $62 \%$ are determined to work at something they don't understand

- $38 \%$ prefer to read IS propaganda while $39 \%$ indicated that they did not mind

Respondents' attitudes towards their thinking styles may indicate their preferences on how they approach challenges in learning etc.:

- $73 \%$ prefer to apply new things they have learnt

- $79 \%$ prefer to consider new ways of thinking

- $71 \%$ think about the future

- $61 \%$ prefer to examine unknown issues to try to understand them

- $73 \%$ prefer to find different solutions when other methods don't work well enough

Respondents' attitudes towards visual stimuli were quite conclusive and were recorded as follows:

- $91 \%$ prefer TV while $9 \%$ prefer reading a book

- $89 \%$ prefer TV while $11 \%$ prefer writing

- $65 \%$ prefer TV while $35 \%$ prefer using the PC

- $89 \%$ prefer TV wile $11 \%$ prefer writing

- $65 \%$ prefer TV while $35 \%$ prefer using the PC

- $91 \%$ prefer TV while $9 \%$ prefer reading a book

- $89 \%$ prefer TV while $11 \%$ prefer writing

There is good evidence here to indicate that visual provisioning of learning might be a more effective method than the presentation of information, concepts and/or ideas solely in a written format.

3) Results and Discussions: The new ISA tasks and activities required individuals or groups to develop an activity; use materials, internet, magazines, textbooks etc and other additional manipulative equipment, experiments, calculators, and computers were also used. The preference items questioned employees and required them indicate a preferred approach to learning ISA concepts and material, here they were asked to indicate whether they preferred approach one (the current way their company is using to deliver ISA programmes) or approach two (where employees, are given little on no instruction or explanation to develop their own ISA programmes).

The two companies that volunteered from the pool of 30 companies that had their CIO's interviewed and they were requested to implement a number of ISA tasks that were identified as constructivist based on our above mentioned criterion. Hence, a total of 81 employees completed the questionnaire and these were collected for comparative analysis to the questionnaires. Here 7 constructivist tasks/activities are presented as samples (each sample aims at raising ISA awareness through the familiarity of the concept is implemented through task).

The creation of new ISA programmes included the development of the following 7 tasks.

\section{Sample Task 1: Email Creation and Antivirus}

Employees were asked to go into groups of 5 and given the task to construct an email message in a given time span (normally 45 minutes) which would be then be sent out (after CIO had scrutinised it for appropriateness and relevance) to the whole company as part of the ISA programme. They were given access to a number of resources (access to the internet, written material on IS etc) from which they were asked to examine and then identify important aspects which needed to be transmitted in the email that they created. They were also asked to make it as creative and as funny as possible. This aspect was introduced to make the activity more fun, kinaesthetic (handling resources, doing something physical) and interesting.
Further to this those who championed this constructivist ISA programme (namely the researcher) were trying to focus on convergent and divergent thinking, possibly by encouraging and balancing fact (actual ISA information) and feasibility (funny cartoon), and striking equilibrium between structure and flexibility (ibid). Some remarkable features were noted by the observers were qualitatively recorded such as; on receiving the end results from the employees, vocal and visible expressions of happiness and jubilation from the groups were experienced. In general all group members were excited and animated on returning their created group effort email, interestingly, different groups even showed their results to each other, and the researcher noted with some element of surprise, that all group members were quite happy and cheerful for completing the task, indicating they had enjoyed that particular session. Some of the groups handed in several different versions of an email, while others had created emails on different ISA concepts even though they were asked to concentrate on one topic or concept. Emails also showed signs of artistic creativity e.g. some of them were presented with illustrations (cartoons, images cut out from magazines etc), while others wrote the messages in differing fonts and differing coloured fonts.

\section{Sample Task 2: Videoed Presentation}

Employees were asked to get into groups of 5 and given the task to use whatever resource they had at their disposal to fulfil the task requirement which was to produce a 2 minute videoed presentation similar to a youtube.com style video on a particular aspect of IS to raise ISA on that concept/topic or aspect.

Again they were given only 45 minutes to complete the task which would then be sent out (after CIO had scrutinised it for appropriateness and relevance) to the whole company as part of the ISA programme. They were given access to a number of resources (access to the internet, written material on IS etc) from which they would source their videoed material. Again creativeness and funniness were important criteria to meet. This aspect was introduced to make the activity more fun and the video presentation involves images (as well as pictures and shapes), which are processed by the right hemisphere of the brain (Torrance and Reynolds [21]). The choice of videoed images was critical to the success of the activity, and the use of the group members themselves to create the video was preferred as this aspect can be observed as being motivational, humanistic and interpersonal, a trait believed to emanate from the right brain and learners are affected by their sense of relatedness to activities that they carry out.

\section{Sample Task 3: Quiz Creation}

Employees were asked to get into groups of 5 and given the task to use whatever resource they had at their disposal to fulfil the task requirement which was to produce a quiz regarding a particular aspect of IS to raise ISA on that concept/topic or aspect.

They were given only 45 minutes to complete the task which would then be sent out (after CIO had scrutinised it for appropriateness and relevance) to the whole company as part of the ISA programme.

One of the criteria was that the quiz question had to be written around an illustrated geometrical shape made up of dotted lines, once they had written the question along the dotted lines, which made up the geometrical shape. The answer, normally a multiple choice also made up the geometrical shape. After which, they were required to follow some steps directing them to cut around the edges of the shape, to facilitate its easiness of being converted into a 3D shape e.g. a cube. That could then be printed out, constructed and displayed on their desk. Six correctly answered and constructed shapes would be eligible and entitled for a prize.

The usage of the illustrated image drawn out of words to a 
question and its subsequent multiple choice answers and the expected construction of the illustration into a 3D image such as a cube were in fact activities.

\section{Sample Task 4: Poster Creation: Importance of Backup}

Employees were asked to get into groups of 5 and given the task to use whatever resource they had at their disposal to fulfil the task requirement which was to produce a poster regarding a particular aspect of IS to raise ISA on that concept/topic or aspect. They were given only 45 minutes to complete the task which would then printed out and distributed (after CIO had scrutinised it for appropriateness and relevance) around the whole company as part of the ISA programme.

They were requested to make it as creative and as funny as possible as with the email task focus was applied on convergent and divergent thinking, with the encouragement of and balancing fact (actual ISA information) and feasibility (funny cartoon), and striking equilibrium between structure and flexibility. Once again employees enjoyed this activity and some of the groups handed in several different versions of the posters they created, and again others created more than one poster on different ISA concepts, without being asked to, possibly indicating enjoyment of the task, which probably has far reaching implications regarding learning and understanding, as Lawless [12] explains that learners who are motivated to learn the material spend more time than those motivated for any other purpose.

\section{Sample Task 5: For and Against Discussion}

Employees were given 45 minutes to complete the following task and they were asked to get into groups of 5 and given the task to use whatever resource they had at their disposal to fulfil the task requirement which was to pick an ISA concept from a set of cards which were placed on the table facing down, then once the group leader had picked up a card that had the ISA concept described the group was then instructed to think up arguments for it and against it and then a nominee was selected from each group who would read out aloud the ISA concept then put their point forward for it while other members of the other groups opposed them, the nominee would then nominate someone from their group to defend the concept. Specifically, the five cards contains the "following for and against" questions: anti-virus software, physical security, firewall, password, file encryption.

Once all group members got a chance to oppose and/or defend a concept, all individuals where sent back to their respective departments within the company to hold similar discussion forums with their colleagues. The fact that we expect the employee to go away to their respective departments to carry out the similar assignment is similar to getting homework to be done in their 'home' departments. Sample Task 6: Approximations

Employees were given 45 minutes to complete the following task and they were asked to get into groups of 2 and given the task to use whatever resource they had at their disposal to fulfil the task requirement which was to guess as accurately as possible the volume capacity of two vessels (e.g. a cup and testtube) then they were asked several questions with illustrations (if necessary) of ISA concept statistics which were related to numbers, and sizes (e.g. which would cause more harm a person given someone their password or someone downloading an attachment from an undisclosed source), the idea here is to encourage dialogue and debate and not find definite answers. All questions were meant to challenge thinking and stimulate discussion, with the hope that the employees go away more informed, conversant and ISA wiser. A follow up answer session gave definite facts to compare against their answers. The groups were then asked to improve the comparisons (in terms of creativity and funniness) so that they could then be emailed out which of the (after CIO had scrutinised it for appropriateness and relevance) around the whole company as part of the ISA programme. Learners who are involved in adventurous and/or exploratory activities may likely experience positive learning outcomes (Bryan and Sullivan-Burstein [5]). Indeed, the employees will be motivated by ensuring that they receive real-life ISA facts and figures.

\section{Sample Task 7: Competition}

Employees were given 45 minutes to complete the following task and were requested to get into groups of 5, to use whatever resource they had at their disposal to fulfil the task requirement which was to produce a method (a set of criteria) of assessing a poster, an email, which would then be used to nominate the best poster or email that was created and the best one would then forwarded for a prize. Here the idea is to get employees in the company to look and read the poster, which they would have otherwise, have ignored and this time become a discerning viewer and judge for an item which was created by colleagues. This should raise awareness of the ISA concept being advertised or propagandized. Whether assignments and tasks are set in learning environment or out of the learning environment (at home) they should be interesting as this improves motivation and learning styles (Fouzder and Markwick [7]).

4) Employees' evaluation: We recorded the opinion of the employees during the implementation of the constructivist ISA, in this case participants were asked to choose one of the two approaches. This provided us with another evaluation criterion to analyse our proposed constructivist ISA programme. Interestingly, all of the 81 respondents, with the exception of one employee, had chosen approach two. I would like to mention that it was wonderful to watch employees showing their developed ISA ideas to each other as they were clearly interested, enthusiastic and some showed genuine happiness towards the sessions at hand. A scene that had never been experienced before by any of the CIO's who were concerned in this study.

All who participated in the sample tasks unanimously agreed that the activities and tasks were far better in terms of interest, higher quality, standard, and were more attractive, when compared to original ISA emails, and information sheets which were generally ignored and had little impact. It has been suggested by Turner [23] that learners should be motivated to carry out learning tasks (such as reading an email) for both enjoyment and information. Though referring to students and their homework, the relevance cannot be ignored, when Bryan and Sullivan-Burstein [5] suggests that those who assign factual information in a difficult or time-consuming manner, or do not have the necessary materials will contribute to learning annoyances (and/or assignment incompletion). Bryan and Sullivan-Burstein [5] also suggested strategies and solutions to combat the above problems, such as reinforcements, graphing, cooperative study teams, homework planners (or in our case ISA planners), and family involvement (or in our case department involvement). Glasser [9] argues that all people need a sense of belonging, freedom, power, and fun. When developing ISA programmes CIO's must recognize that these needs motivate learner behaviours and attitudes.

5) Overall Evaluation: The overall and general evaluation for the constructivist ISA sample programme was considered to be very positive and very much in favour of it. It was felt that in designing instructional activities whether for the work environment or for the department, or home, they should endeavour to incorporate constructivist ideas. Spitzer [19] ascertains the incorporation of certain important motivator into the context of learning activities, these being: action; fun; choice; social interaction; error tolerance; 
measurement; feedback; challenge; and recognition (Spitzer [19]).

Qualitatively speaking, the inferences made by participating employees were that constructivist approach endeavours to encourage them to recognize and foster a reflective, introspective and learning attitude towards their development and understanding of IS principles, concepts and raise their awareness of it to better levels of understanding and respect. It fosters an approach and an outlook that says "as a CIO I am aware of my mind set, and through this awareness, I appreciate my strengths and understand where I can contribute in enhancing my colleagues work effort, and at the same time it gives me the confidence and self assurance in seeking, recognising and encouraging my colleagues to contribute to my work effort. Indeed the workplace is ours, the employees are benefiting from us and we from them in an information secure place of work". As advocated by Ripley [17] facilitators of learning and training are more ready to accept the fact that they "must begin to think of it as our learning environment" where the biggest change for educators/trainers is in deciding to share the role that has traditionally been individual: to share the goals, decisions, work environment training and instruction, responsibility for employees, assessment of employee learning and training, problem solving, and learning management. As a consequence, this should promote a collaborative and teamwork atmosphere within the company as a whole, thus improving the ISA programme.

Other qualitative phenomena which were reported, though not quantified, by the researcher after implementing the sample constructivist ISA programme, was the decrease in the numbers of emails ignored (as evidenced by the number of read receipt received by the $\mathrm{CIO}$ ) and poster read (as evidenced by number of assessed poster slips completed for the competition), and the solutions to the tasks which the employees themselves delivered was also noted as being more creative than previously experienced e.g. the employees had never before being instructed to develop or create ISA programme material etc. As for employee feedback, when asked by the researcher about what their thoughts were concerning the tasks, they viewed them as more interesting, fun and enjoyable.

The creativity illustrated in the presented tasks and the noted "voluntary/self-extended" tasks (i.e. doing more than what was required) can be taken as an indication of employees' willingness at becoming more autonomous ISA learners. Though this is not the subject of this research, when it did occur it was noted and it was usually accompanied by expressions of enjoyment in doing the tasks. The researcher wanted to briefly find out the possible reasons why this may have occurred. Surprisingly, Torrance and Reynolds [21] regarded self directness or self acting as a right hemispheric function, and in other studies it has been found that autonomous learners are more able to complete tasks than learners who are not intrinsically motivated and self-directed (Bronstein and Ginsburg [4]). Now interactive tasks are attributed to the right hemisphere of the brain as Torrance et al. [22] and Torrance and Reynolds [21] considered activities such as creative output, playful problemsolving, playful (humorous, fun) learning as right-brained activities. We may assume that because the many of the tasks were quite interactive and learner-centric it stimulated creativity and encouraged the self directness or self acting exhibited in the employees' who 'self-extended' their tasks by doing more than what was required, and found it enjoyable to do so, this needs further investigation and is briefly touched on here, as this is not the focus of this study. Further to this, all the employees agreed that they had noticed a great difference in their own reactions towards ISA which was positive and in their own words "great", "fantastic" which were some of the words used to describe the sessions and tasks. These signs in today's work environment may be seldom experienced, especially in the fields of Information Security Awareness.

6) Difficulties with Constructivist ISA programme (Approach Two): During the employee interviews conducted by the researcher (Boujettif) a number of opinions surfaced which were deeply expressed by the employee regarding the delivering ISA programme in this manner and these were duly noted and they identified a number of obstacles to implementing the constructivist ISA methodology effectively (approach two). Many employees listed several valid obstacles. Of these responses, the major ones have been documented.

However, in implementing this constructivist ISA programme some important disadvantages and difficulties were encountered, and should be considered. The main difficulties were:

- It is more time consuming: as preparation time is needed to organize constructivist ISA tasks and activities. In many cases one cannot just photocopy and distribute ISA material, they have to be developed into interactive tasks that challenge individuals and groups.

- The lack of resources, material and equipment. Additional expenses were incurred; the provision of certain resources and equipment were necessary. One CIO indicated, "Our resources are limited and old and newer ones are too expensive to kit out for this approach".

- Lack of session time. There is not enough working time to ensure that all the employees have thoroughly understood and worked out and contributed effectively enough. Especially when materials and equipment need to be used and the proposed ISA syllabus needs to be covered in a specified time, there is no way this approach will ensure coverage of the syllabus, in good enough time.

- No time for adequate session planning using approach two.

- Additional manpower; as more than one facilitator (including the CIO) was used to prepare a sessions and tasks.

- Many meetings were necessary for constructivist ISA programme tasks to be fully effective as collaborative work was necessary, again a rather time consuming task.

- Due to employees' divergent cognitive/personality differences and preferences, deliberations on task inclusion or exclusion were tense, difficult, and complex, and at times the misunderstandings were rather callous and argumentatively harsh.

However, such disadvantages can be resolved in one way or another. For example, with regards to the argumentative misunderstandings due to divergent cognition, then the mediator (mostly likely the CIO or the nominated lead ISA champion, will have to be employed to resolve any conflicts that might crop up, they will have the ability to empathise and perceive both parties side of the story, and they will be in a position to direct both parties towards a common goal and ultimately towards mutual collaboration. As with all serious ISA programmes, it will involve commitment from the employees involved, as well as the senior managers, who need to provide for planning, resources, time, assessment, and above all else their positive support, in order to fully appreciate and benefit from the positive consequences of employing this constructivist programme.

Nevertheless, the first important and most often criticised issue which was highlighted above was the time factor. There is no doubt that initially, constructivist ISA is time consuming, it requires more planning, professional development, and action, but once the employees have been adequately trained, and the planning has also put into place certain support systems, then this factor becomes less of an issue and will inevitably decrease as the full effects of the ISA 
programme takes effect, such as; employees reported professional skills being developed such as planning, preparation, and increase in productivity, as a result of their personally perceived increase in motivation to comprehend and understand information security and of course their awareness to it also improved. Furthermore, some of the employees even indicated that their interpersonal support between colleagues was improved, as they gained a greater understanding of themselves, as well as gaining an insight into the positive differences of others, thus leading to the acceptance of others for mutual gain and benefit particularly concern ISA and their new found responsibilities.

The findings from this research indicate that there has been a positive impact in the improving ISA, and once more, this impact was viewed as enthusing by one CIO. At the company level, we expect there to be broader ramifications and/or inferences that this new approach may (if applied) have, impacting on other areas of concern such as (company training, human resources department, etc) and we also anticipate there to be wider positive implications on the design of general information security delivery. These observations of course point to the need for further studies in this area.

\section{CONCLUSIONS}

The historical precedents of constructivist came from the research work of Dewey, Montessori, Piaget, Bruner and Vygotsky. Fosnot [6] and summaries of constructivist as a constructivist epistemology assuming learners construct their own knowledge on the basis of interaction with their environment. These assumptions are at the heart of approach two where it meets the age old traditional learning expectations, that being, every facilitator has high expectations for the learners. Facilitators want learners not only to understand the material, but also to develop higher order thinking skills, such as analysis, reasoning, and problem solving. Unfortunately, the day to day practices in most companies who want to encourage their employees to improve their ISA awareness and learn ISA concepts only deliver superficial ideas and low level skills. Without a strong conceptual foundation and without analysis, reasoning and other skills, employees will continue to adopt superficial and formulaic approaches to problem solving (Leonard, Gerace, and Dufresne [13]) and in terms of ISA they gain only a superficial attitude and awareness towards ISA.

Employees have experienced traditional practices of delivering ISA, where they are force fed a diet of factual information to be rote learned. Many employees expect to be filled up with knowledge, like they are empty glasses waiting to be filled. Employees may also be blamed for this traditional paradigm as they tend to expect experts to transfer the knowledge to them, much like one fills a bottle with liquid. If so called experts do not fulfil their traditional roles employees might be confused and have difficulty engaging as intended by the expert. Just as experts have to learn how to facilitate learning from a constructivist point of view, so too must employees learn how to learn.

This study made use of constructivist methods to enhance employee awareness of information security ideas and concepts through the interactive collaboration of employees in playing a more centric role, where they took on the responsibility of developing and enthusing the ISA programme with interactive and enjoyable activities that are more likely to create interest from the employees and with the aim of improving information security awareness. To this end, the implications of the constructivist approach to information security have resulted, in this limited study, to a perceived improvement in information security awareness. Even though, they are encouraging, curious, and thought provoking.

\section{REFERENCES}

[1] Aknolu, O. and Tandoan, R. (2007), The Effects of Problem-Based Active Learning in Science Education on Students' Academic Achievement, Attitude and Concept Learning; Eurasia J. Math, Sci. Tech. Education, $3(1), 71-81$.

[2] Ann, M L., Timothy, C., and Laubach, A. (2001). Students' Science Perceptions and Enrollment Decisions in Differing Learning Cycle Classrooms, J. Research in Science Teaching, 38(9):1029-1062.

[3] Anzai, Y and Simon, H.A. (1979). The theory of learning by doing. Psychological Review, 86:124-140.

[4] Bronstein, P. and Ginsberg, G.S. (1993). Family factors related to children's intrinsic/extrinsic motivational orientations and academic performance. Childhood Development. 64:1461-1474.

[5] Bryan, T and Sullivan-Burstein, K. (2004). Improving Homework Completion and Academic Performance: Lessons from Special Education. Theory Into Practice. 43(3):213-219.

[6] Fosnot, C. T. (1996). Constructivism: A psychological theory of learning. In C. T. Fosnot (Ed.), Constructivism: Theory, perspectives, and practice. pp. 8-33. New York, NY: Teachers College Press, Columbia University.

[7] Fouzder, N.B. and Markwick, A. J. W.(2000). Self-Perception, Individual Learning Style and Academic Achievement by a Pair of Bilingual Twins in a Secondary School Int. J. Science Education. 22(6):583-601.

[8] Gallet, C. J. (1998). Problem-solving teaching in the chemistry laboratory: Leaving the cooks. J. Chemical Education, 75(1):72-77.

[9] Glasser, W. (1996). Then and Now. The Theory of Choice. Learning. 25(3):20-22.

[10] Jenkins, E. W. (2000). Constructivism in school science education: Powerful model or the most dangerous intellectual tendency? Science and Education, 9:599-610.

[11] Katsikas, S.K. (2000). Health care management and information systems security: awareness, training or education? Int. J. Medical Informatics, 60:129-135.

[12] Lawless, C. (2000). Using Learning Activities in Mathematics: Workload and Study Time. Studies in Higher Education. 25(1):97-111.

[13] Leonard, W.J., Gerace, W.J., and Dufresne, R.J., (1999). Concept-Based Problem Solving: Making concepts the language of physics*. Available on the internet at: http://srri.umass.edu/files/gerace-1999cbp.pdf (Accessed on: 2009 March 19)

[14] Maria, P. and Rosetta, Z. (2005). Teachers' use of the constructive 'attitude'. Preliminary Research Findings CERME4, pp. 265-274.

[15] Naylor, S. and Keogh, B. (1999). Constructivism in classroom: Theory into practice. Journal of Science Teacher Education. 10:93-106.

[16] Pickens, J. (2005). Chapter 43: Attitudes and Perceptions. In: Borkowski, N., (eds). Organizational Behavior in Health Care. Sudbury, MA: Jones and Bartlett Publishers.

[17] Ripley, S. (1998). Collaboration between General and Special Education Teachers. Teaching Strategies. Journal of Early Education and Family Review. 5(4):16-20

[18] Runco, M.A and Charles, R.E. (1997). Developmental Trends in Creative Potential and Creative Performance. In M. Runco (Ed), The Creativity Research Handbook. Vol: 1. New York: Hampton.

[19] Spitzer, D. R. E, 1(996). Motivation: The Neglected Factor in Instructional Design. Educational Technology. 36(3):45-49.

[20] Stanton, J. M., Stam, K. R., Guzman, I., and Caldera, C. (2003). Examining the linkage between organizational commitment and information security. Proceedings of the IEEE Systems, Man, and Cybernetics Conference. Washington, DC.

[21] Torrance, E. P. and Reynolds, C.R. Perceived Changes in Styles of Learning and Thinking (Hemisphericity) Through Direct and Indirect Training. J. Creative Behaviour 12 (1980) 247-252.

[22] Torrance, E. P., Reynolds, C. R., and Kalbsonnis, B. Childrens' form of your style of learning and thinking: Preliminary norms and technical data. The Gifted Child Quarterly. 1979, 13, 4

[23] Turner, D. Y. (1992). Motivating Reluctant Readers: What Can Educators Do? Reading Improvement. 29(1):50-55.

[24] Von Glasersfeld, E. (1995). Radical constructivism: A way of knowing and learning. Washington, DC: Falmer.

[25] Von Solms, B. (2000). Information Security - The Third Wave. Computers and Security. 19:615 - 620. 